Check for updates

Cite this: Food Funct., 2019, 10, 3161

\title{
Ocimum basilicum var. purpurascens leaves (red rubin basil): a source of bioactive compounds and natural pigments for the food industry
}

\author{
Filipa Fernandes, (D) ${ }^{a}$ Eliana Pereira, (D) a Ana Círić, (DD ${ }^{b}$ Marina Soković, (D) ${ }^{b}$ \\ Ricardo C. Calhelha, ${ }^{a}$ Lillian Barros (D)*a and Isabel C. F. R. Ferreira (D)*a
}

\begin{abstract}
Ocimum basilicum var. purpurascens (red rubin basil) is a basil variety rich in anthocyanin compounds, commonly used in the food industry as an aromatic plant. In this study, the nutritional and chemical compositions of red rubin basil leaves were analysed, as well as, the antimicrobial activity and hepatotoxicity of their hydroethanolic extract. Carbohydrates were the main macronutrients present, with glucose being the major free sugar. Quinic acid was the most abundant organic acid, while $\gamma$-tocopherol was the highest tocopherol isoform found. $\alpha$-Linolenic acid was the major fatty acid of the twenty identified compounds. Regarding polyphenols, twenty-six molecules were identified (thirteen non-anthocyanin and thirteen anthocyanin compounds), with rosmarinic acid being the main non-anthocyanin molecule and cyanidin-3-(6,6'-di-p-coumaroyl)-sophoroside-5-glcucoside the most abundant anthocyanin. These compounds could be related to the antimicrobial activity observed in this study. Thus, this variety could be considered a good source of value added molecules for the food industry.
\end{abstract}

Received 19th March 2019,

Accepted 2nd May 2019

DOI: 10.1039/c9fo00578a

rsc.li/food-function flavonoid class. ${ }^{5}$ These compounds, besides being responsible for the colour, exhibit other functions, such as the attraction of pollinating agents, antioxidant potential (which contributes to the protection of plants against certain diseases), and protection against herbivorous attacks and abiotic stress. In addition to these properties, they still intervene against ultraviolet radiation and against viral and microbial contamination. ${ }^{5}$

The use of anthocyanins as food colorants is authorised in several countries, including countries of the European Union (E163), the United States (which classifies them as certified colour additives) and Asia. ${ }^{6}$ In addition to the colouring properties, these molecules exhibit functional properties, show antioxidant, anti-inflammatory, and neuroprotective activities, reduce the incidence of cardiovascular disease, intervene against obesity and control the metabolic syndrome. ${ }^{6}$

The variety Ocimum basilicum var. purpurascens (red rubin basil), belongs to the Ocimum basilicum L. species (commonly known as basil); it is an annual aromatic plant from the Lameaceae family ${ }^{7}$ and it is characterized by a purple colour, due to the high concentration of anthocyanins present in its leaves. ${ }^{8}$ Traditionally, O. basilicum is used as a condiment in the food industry; however, several studies have revealed that its action goes beyond the concept of a spice, due to its therapeutic properties in traditional medicine. ${ }^{7}$ Thus, it has been used in the treatment of several diseases, such as cough, headache, kidney dysfunction, acne treatment, abdominal pain, inflammation, diabetes, and eye diseases, owing to its stimu- 
lating, anti-spasmodic, carminative, and digestive actions, and antifungal, insecticidal, and antibacterial activities. ${ }^{9}$ Regarding the application of this species in the phytopharmaceutical sector, no studies are available in the literature; in contrast, there are some studies about $O$. basilicum coloured varieties and cultivars. ${ }^{2,8}$ Concerning the red rubin basil (O. basilicum var. purpurascens), there are studies describing the nutritional compositions of dry and fresh leaves, ${ }^{10,11}$ and also the phenolic compositions of different extracts, such as hydromethanolic and aqueous extracts. ${ }^{8,12,13}$ Moreover, the individual anthocyanin profile has also been reported, especially using the methanolic extract acidified with $0.1 \% \mathrm{HCl}^{14}$ The antioxidant activity has also been explored, studying the hydroethanolic $(60: 40, \mathrm{v} / \mathrm{v})$ and acidified methanolic $(0.2 \mathrm{M} \mathrm{HCl})$ extracts. $^{8,13}$ However, and despite having performed these studies, the present work shows a complete and detailed evaluation of red rubin basil originating from Portugal, evaluating for the first time its nutritional and chemical compositions in dried leaves, and also the antimicrobial and hepatotoxic activities of a hydroethanolic extract of this variety.

Therefore, the present study reveals novelty, evaluating different characteristics, such as nutritional parameters (proteins, ash, fat, carbohydrates and energy), chemical compositions (free sugars, organic acids, tocopherols, fatty acids, and phenolic compounds), and antimicrobial activity (against Gram-positive and Gram-negative bacteria, and fungi) of O. basilicum var. purpurascens leaves (red rubin basil), a scarcely studied variety. In addition, this work intends to disclose the functional characteristics of anthocyanins, which not only have colourant capacity, but also provide health benefits.

\section{Materials and methods}

\subsection{Sample preparation}

The Ocimum basilicum var. purpurascens (Lameaceae) variety was provided by an organic farmer (Cantinho das Aromáticas, Vila Nova de Gaia, Portugal). Afterwards, it was placed to grow in a greenhouse at the Polytechnic Institute of Bragança and collected during September 2017. The plant parts were separated through a mechanical procedure, selecting only the fresh coloured leaves. Afterwards, with the purpose of drying the sample, the leaves were lyophilized (FreeZone 4.5, Labconco, Kansas City, MO, USA), reduced to a fine dried powder ( 20 mesh), mixed to obtain a homogeneous sample and stored in a place protected from light and heat, until further analysis.

\subsection{Determination of the colour of leaves}

The colour parameters were evaluated in fresh leaves and dry leaves, according to a procedure described by Pereira et al. ${ }^{15}$ The colour was measured using a colorimeter (model CR-400, Konica Minolta Sensing, Inc., Osaka, Japan) with an adapter for granular materials (model CR-A50). The measurements were made in the CIE $L^{*} a^{*} b^{*}$ colour space, using the illuminant $\mathrm{C}$ and a diaphragm aperture of $8 \mathrm{~mm}$. Data were pro- cessed with the "Spectra Magic Nx" (version CM-S100W 2.03.0006) software, from Konica Minolta.

\subsection{Nutritional characterization of leaves}

The macronutrient composition was estimated following the AOAC $^{16}$ procedures. The crude protein $(N \times 6.25)$ was determined by the macro-Kjeldahl method (AOAC 991.02); while the fat content was determined by extracting the dry sample with petroleum ether using a Soxhlet apparatus (AOAC 989.05); ash was estimated by incineration at $550 \pm 15{ }^{\circ} \mathrm{C}$ (AOAC 935.42). Total carbohydrates were calculated from the difference and the energy was estimated using the following equation: Energy $(\mathrm{kcal})=4 \times(\mathrm{g}$ protein $+\mathrm{g}$ carbohydrates $)+9 \times(\mathrm{g}$ fat $)$.

\subsection{Chemical compositions of leaves}

Free sugars were analysed using a High Performance Liquid Chromatography system coupled to a refraction index detector (HPLC-RI, Knauer, Smartline system 1000), according to a procedure previously described by Barros et al. ${ }^{17}$ The compounds were identified by chromatographic comparisons with authentic standards $(\mathrm{D}(-)$-fructose, $\mathrm{D}(+)$-sucrose, $\mathrm{D}(+)$-glucose, $\mathrm{D}(+)$ trehalose and $\mathrm{D}(+)$-raffinose pentahydrate), purchased from Sigma-Aldrich (St Louis, MO, USA), and also melezitose which was applied as the internal standard and used in the quantification method. The sugar concentration was expressed in $\mathrm{mg}$ per $100 \mathrm{~g}$ of fresh weight ( $\mathrm{fw}$ ).

Organic acids were evaluated using an Ultra-Fast Liquid Chromatography system (UFLC, Shimadzu 20A series, Kyoto, Japan) coupled to a diode array detector, according to a method described by Barros et al. ${ }^{17}$ The quantification was performed using calibration curves obtained from commercial standards $(\mathrm{L}(+)$-ascorbic acid, citric acid, malic acid, oxalic acid, shikimic acid, succinic acid, fumaric acid and quinic acid), purchased from Sigma-Aldrich (St Louis, MO, USA). The results were expressed in mg per $100 \mathrm{~g}$ of fresh weight (fw).

Tocopherols were determined following a method described by Barros et al., ${ }^{17}$ using a HPLC system (Knauer, Smartline system 1000) coupled to a fluorescence detector (FP-2020; Jasco, Easton, USA) and programmed for excitation at $290 \mathrm{~nm}$ and emission at $330 \mathrm{~nm}$. The quantification was carried out based on calibration curves obtained from commercial standards ( $\alpha-, \beta-, \gamma-$, and $\delta$-isoforms, Matreya, Pleasant Gap, PA, USA), using tocol as the internal standard (Matreya, Pleasant Gap, PA, USA). The results were expressed in $\mathrm{mg}$ per $100 \mathrm{~g}$ of fresh weight (fw).

Fatty acids were determined using a gas chromatography system coupled with a flame ionization detector (GC-FID, DANI model GC 1000, Contone, Switzerland). The separation was achieved with a Macherey-Nagel (Düren, Germany) column (50\% cyanopropyl-methyl-50\% phenylmethylpolysiloxane, $30 \mathrm{~m} \times 0.32 \mathrm{~mm}$ i.d. $\times 0.25 \mu \mathrm{m} d_{\mathrm{f}}$ ), following a methodology previously described by Barros et al. ${ }^{17}$ Fatty acids were identified by comparing the relative retention times of FAME peaks from samples with commercial standards (FAME reference standard mixture, standard 47885-U, Sigma-Aldrich, St Louis, MO, USA). The results were expressed in relative percentages. 


\subsection{Phenolic compound composition of a leaf extract}

\subsubsection{Non-anthocyanin compounds}

Extraction. The sample ( $1 \mathrm{~g})$ was extracted through a maceration methodology with ethanol/water $(80: 20 \mathrm{v} / \mathrm{v} ; 30 \mathrm{~mL})$, in $1 \mathrm{~h}$ at room temperature. After the maceration process the supernatant was filtered (Whatman $\mathrm{N}^{\circ} 4$ paper) and the plant residue was re-extracted with the same extraction solvent. Ethanol was evaporated at $40{ }^{\circ} \mathrm{C}$ (rotary evaporator Büchi R-210, Flawil, Switzerland), and the remaining aqueous phase was lyophilized (FreeZone 4.5, Labconco, Kansas City, MO, USA). The lyophilized extract was dissolved in ethanol/water $(20: 80 \mathrm{v} / \mathrm{v})$ in a concentration of $5 \mathrm{mg} \mathrm{mL} \mathrm{mL}^{-1}$ and filtered ( $0.2 \mu \mathrm{m}$ nylon filters) into an amber vial for the phenolic compound evaluation. ${ }^{18}$

Analytical method. The chromatographic data were acquired using a Dionex Ultimate 3000 UPLC (Thermo Scientific, San Jose, CA, USA), coupled to a diode array detector (280, 330, and $370 \mathrm{~nm}$ ) and an electrospray ionization mass detector (Linear Ion Trap LTQ XL, Thermo Finnigan, San Jose, CA, USA), working in the negative mode. The chromatographic separation was performed using a Waters Spherisorb S3 ODS-2 C18 ( $3 \mu \mathrm{m}, 4.6 \mathrm{~mm} \times 150 \mathrm{~mm}$, Waters, Milford, MA, USA) column at $35{ }^{\circ} \mathrm{C}$. The compounds were identified considering the retention time, and UV-Vis and mass spectra in comparison with available standards and with literature data. Calibration curves of the available phenolic standards were constructed based on the UV-Vis signal in order to perform quantitative analysis. In the case of unavailable commercial standards, the compounds were quantified via the calibration curve of the most similar standard available. The results were expressed as $\mathrm{mg} \mathrm{g}^{-1}$ of extract. ${ }^{18}$

2.5.2. Anthocyanin compounds. The sample (1 g) was extracted using the same methodology described above; thus the extraction solvent (ethanol/water; $80: 20 \mathrm{v} / \mathrm{v}$ ) was acidified with $0.5 \%$ of trifluoroacetic acid, according to a procedure described by Jabeur et al. ${ }^{18}$

Analytical method. The chromatographic analysis followed a procedure previously described by Gonçalves et al., ${ }^{19}$ with a modification regarding the column applied. The separation was achieved using an AQUA ${ }^{\circledR}$ (Phenomenex) reverse phase $\mathrm{C}_{18}$ column $(5 \mu \mathrm{m}, 150 \times 4.6 \mathrm{~mm}$ i.d $)$ thermostatted at $35{ }^{\circ} \mathrm{C}$, using a UPLC-DAD-ESI/MSn system previously mentioned. Detection was carried out using a DAD (520 nm) and a mass spectrometer (Linear Ion Trap LTQ XL, Thermo Finnigan) equipped with an ESI source, operating in positive mode. Identification of compounds was performed using the retention time, and UV-Vis and mass spectral data in comparison with the available standards and literature review. The results were expressed in $\mathrm{mg} \mathrm{g}^{-1}$ of extract.

\subsection{Antimicrobial activity of the $\boldsymbol{O}$. basilicum var. purpurascens leaf extract}

The antimicrobial activity was evaluated using the hydroethanolic extract prepared according to the procedure described in section 2.5.1, and by applying a methodology previously described by Carocho et al. ${ }^{20}$ In this assay Gram-negative bac- teria (Enterobacter cloacae (ATCC (American Type Culture Collection) 35030), Escherichia coli (ATCC 35210) and Salmonella typhimurium (ATCC 13311)) and Gram-positive bacteria (Bacillus cereus (clinical isolate), Listeria monocytogenes (NCTC (National Collection of Type Cultures) 7973) and Staphylococcus aureus (ATCC 6538)) were used and the minimum inhibitory (MIC) and minimum bactericidal (MBC) concentrations were determined by using the microdilution method, and further expressed in $\mathrm{mg} \mathrm{mL}^{-1}$.

For the antifungal activity, the procedure previously described by Carocho et $a .^{20}$ was also followed, using Aspergillus fumigatus (ATCC 1022), Aspergillus niger (ATCC 6275), Aspergillus ochraceus (ATCC 12066), Penicillium funiculosum (ATCC 36839), Penicillium ochrochloron (ATCC 9112) and Penicillium verrucosum var. cyclopium (food isolate). The minimum inhibitory concentration (MIC) and minimum fungicidal concentration (MFC) were also determined by using the microdilution method, and further expressed in $\mathrm{mg} \mathrm{mL}^{-1}$.

Streptomycin, ampicillin, ketoconazole and bifonazole were used as positive controls for antibacterial and antifungal activities, respectively.

\subsection{Hepatotoxicity evaluation of the leaf extract}

The hydroethanolic extract was dissolved in water at a concentration of $8 \mathrm{mg} \mathrm{mL} \mathrm{m}^{-1}$, and tested against a primary cell culture obtained from porcine liver (PLP2). Ellipticine (Sigma-Aldrich, St Louis, MO, USA) was used as a positive control and the results were expressed as $\mathrm{GI}_{50}$ values (sample concentration that inhibits the growth of cells by $50 \%$ ), in $\mu \mathrm{g} \mathrm{mL}{ }^{-1}$.

\subsection{Statistical analysis}

The leaves of $O$. basilicum var. purpurascens were collected to give origin to three different groups and all assays were carried out in triplicate; the results were expressed as the mean value and standard deviation (SD). The colour parameter results were compared by means of a Student's $t$ test to determine the significant difference among samples, with $\alpha=0.05$ (IBM SPSS Statistics, Version 23.0, IBM Corp., Armonk, New York, USA).

\section{Results and discussion}

\subsection{Colour evaluation of leaves}

Colour is a very important factor in the choice of food products, emphasizing the matrices with more accentuated colours as the most interesting. ${ }^{21}$ The results of the chromatic analysis in the CIE $L^{*} a^{*} b^{*}$ colour space of $O$. basilicum var. purpurascens (fresh leaves and dried powder) are shown in Table 1. Lightness $\left(L^{*}\right)$ shows a scale that ranges between 0 and 100 and $a^{*}$ (from green to red) and $b^{*}$ (from blue to yellow) show a scale that diverges between -120 and $120 .^{22}$ The colour in fresh leaves was evaluated and $L^{*}$ presented a value of $36 \pm 1$, and the parameters $a^{*}$ and $b^{*}$ were found to be $7.6 \pm 0.1$ and $1.11 \pm 0.05$, respectively. Moreover, the red rubin basil dried powder $L^{*}$ parameter presented a value of $31 \pm 1$, while on the other hand, the variables $a^{*}$ and $b^{*}$ presented 
Table 1 Physical (colour $-\mathrm{CIE} L^{*} a^{*} b^{*}$ ) and nutritional parameters of O. basilicum var. purpurascens (mean \pm SD)

\begin{tabular}{llll}
\hline Colour & Fresh leaves & $\begin{array}{l}\text { Lyophilized } \\
\text { leaf powder }\end{array}$ & $p$-Value \\
\hline$L^{*}$ & $36 \pm 1$ & $31 \pm 1$ & $<0.01$ \\
$a^{*}$ & $7.6 \pm 0.1$ & $5.3 \pm 0.2$ & $<0.01$ \\
$b^{*}$ & $1.11 \pm 0.05$ & $3.7 \pm 0.1$ & $<0.01$ \\
\hline
\end{tabular}

Nutritional value

Moisture (g per $100 \mathrm{~g}$ fw)

Ash ( $g$ per $100 \mathrm{~g}$ fw)

Proteins ( $g$ per $100 \mathrm{~g}$ fw)

Fat ( $\mathrm{g}$ per $100 \mathrm{~g} \mathrm{fw}$ )

Carbohydrates (g per $100 \mathrm{~g}$ fw)

Energy (kcal per $100 \mathrm{~g}$ fw)

fw - fresh weigh. $L^{*}$ - lightness; $a^{*}$ chromatic axis from green $(-)$ to red $(+) ; b^{*}$, chromatic axis from blue $(-)$ to yellow $(+)$.

values of $5.3 \pm 0.2$ and $3.7 \pm 0.1$, respectively. According to these results it was evident that lyophilisation influences the colour of the studied samples. Through the evaluation of the parameter $L^{*}$ it was verified that the fresh leaves have a lighter colour compared to the lyophilized leaf powder. For the $a^{*}$ parameter, a higher value in the fresh leaves was detected in comparison with that in the lyophilized leaf powder; therefore the former showed a higher red tone than the lyophilized sample. The $b^{*}$ parameter showed that the fresh leaves presented a bluer tonality in comparison with the lyophilized leaves. With these results it is possible to verify that the lyophilisation process slightly decreased the purple colour, which may be related to a minor degradation of the anthocyanin content. $^{21}$

Several studies have been carried out in order to understand the influence of dehydration processes in the preservation of colour and/or pigmented compounds (e.g. anthocyanins). In a report by Lima-Corrêa et al., ${ }^{23}$ the influence of drying conditions (heat drying and lyophilisation) on the colour of fresh and dried leaves of Ocimum basilicum $\mathrm{L}$ was evaluated. The results showed that $L^{*}$ values decreased after heat drying, indicating a darker colour of dried basil leaves in comparison with that of the fresh leaves. While the parameter $a^{*}$ increased significantly, indicating that the leaf colour became less green, the $b^{*}$ parameter was not affected by the air temperature, but decreased on increasing the temperature to $30^{\circ} \mathrm{C}$. Considering the results and comparing the two dehydration processes, it was evident that heat drying influences more the loss of colour in comparison with the lyophilisation process. The percentage of the light colour decrease $\left(L^{*}\right)$ was higher in the heat drying process $(26.9 \%)$ than in the lyophilisation process $(11.8 \%)$, but in both dehydration processes there was a loss of colour in parameters $a^{*}$ and $b^{*}$ in comparison with the fresh leaves, and this loss was more evident when the heat drying process was applied.

Moreover, Luna-Vital et al. ${ }^{24}$ and Jiang et al. ${ }^{21}$ demonstrated that the loss of colour in natural matrices, under the influence of external factors (e.g. $\mathrm{pH}$ and temperature), is related to anthocyanin degradation, as the decrease in the total anthocyanin content is directly proportional to the decrease in the $a^{*}$ value (blue to red).

Thus, in order to preserve plant matrices, such as leaves, a drying process should be applied, and the lyophilisation process has been demonstrated as the most efficient methodology with less degradation associated. ${ }^{23}$

\subsection{Nutritional characterization of leaves}

The results concerning the nutritional value evaluation of O. basilicum var. purpurascens leaves are presented in Table 1. From the results, it is visible that the macronutrients present in higher amounts are carbohydrates $(7.17 \pm 0.07 \mathrm{~g}$ per $100 \mathrm{~g}$ $\mathrm{fw})$, followed by ash $(2.84 \pm 0.01 \mathrm{~g}$ per $100 \mathrm{~g} \mathrm{fw})$, and proteins $(2.3 \pm 0.1 \mathrm{~g}$ per $100 \mathrm{~g} \mathrm{fw})$. The fat content was very low, presenting values of $0.36 \pm 0.02 \mathrm{~g}$ per $100 \mathrm{~g}$ fw. Regarding the moisture, this plant exhibited a value of $85 \pm 2 \mathrm{~g}$ per $100 \mathrm{~g}$, revealing a high percentage of water in its constitution. In general, the energy level of $O$. basilicum var. purpurascens leaves was $41.22 \pm$ $0.04 \mathrm{kcal}$ per $100 \mathrm{~g}$ fw.

El-Hadidy and Mostafa ${ }^{10}$ also studied the nutritional value of red rubin basil fresh leaves and the results agreed with those presented in this work. Carbohydrates were also the major macronutrient $(4.70 \pm 0.91 \%)$, followed by proteins $(3.24 \pm 0.23 \%)$. The ash content was $1.78 \pm 0.11 \%$. The sample also presented a moisture content of $84.40 \pm 0.46 \%$. Moreover, Murillo-Amador et al. ${ }^{11}$ studied the nutritional contents of twenty-four Ocimum cultivars under two cultivation environments, including red rubin basil. The results were higher than those presented herein, revealing protein, ash and fat contents of $16.36 \%, 15.05 \%$, and $2.14 \%$, respectively. Nevertheless, the moisture content $(83.44 \%)$ was similar to the one obtained in our study, as also the energetic value (3951.64 $\mathrm{cal} \mathrm{g}^{-1}$ ), which also presented a comparable content to the herein studied sample $\left(3247 \pm 3 \mathrm{cal} \mathrm{g}^{-1}\right)$. Pereira et al. ${ }^{25}$ studied the nutritional value of green Ocimum basilicum $\mathrm{L}$. and due to the fact that results were expressed in dry weight, a direct comparison with the present study is not possible. However, carbohydrates were also the major macronutrients $(82.49 \pm 0.12 \mathrm{~g}$ per $100 \mathrm{~g}$ $\mathrm{dw})$, followed by the ash content $(15.60 \pm 0.14 \mathrm{~g}$ per $100 \mathrm{~g} \mathrm{dw})$, while proteins and fat were the minor macronutrients present ( $0.89 \pm 0.04$ and $1.03 \mathrm{~g}$ per $100 \mathrm{~g} \mathrm{dw}$, respectively).

The differences found in the mentioned studies may be due to different growing conditions of this plant species, which have a great influence on the chemical composition.

\subsection{Chemical composition of leaves}

The chemical compositions regarding free sugars, organic acids, tocopherols and fatty acids of O. basilicum var. purpurascens leaves are shown in Table 2.

Four soluble sugars were detected in the studied plant leaves, and were identified as two monosaccharides (glucose and fructose) and two disaccharides (sucrose and trehalose). Glucose was the main free sugar detected $(42 \pm 2 \mathrm{mg}$ per $100 \mathrm{~g}$ $\mathrm{fw}$ ), while sucrose was the molecule identified in the lowest concentration $(17 \pm 1 \mathrm{mg}$ per $100 \mathrm{~g} \mathrm{fw})$. Fructose and threalose 
Table 2 Sugar, organic acid, tocopherol, and fatty acid compositions of $O$. basilicum var. purpurascens leaves (mean \pm SD)

\begin{tabular}{lcll}
\hline \multicolumn{3}{l}{ Sugars $(\mathrm{mg}$ per $100 \mathrm{~g}$ fw) } & \multicolumn{2}{l}{ Fatty acids $(\%)$} \\
\hline Fructose & $23 \pm 1$ & C6:0 & $0.029 \pm 0.001$ \\
Glucose & $42 \pm 2$ & C10:0 & $0.175 \pm 0.005$ \\
Sucrose & $17 \pm 1$ & C12:0 & $0.114 \pm 0.005$ \\
Trehalose & $20 \pm 1$ & C13:0 & $4.32 \pm 0.04$ \\
Total & $102 \pm 1$ & C14:0 & $0.462 \pm 0.004$ \\
Organic acids $(\mathbf{m g}$ per $\mathbf{1 0 0} \mathbf{g} \mathbf{f w})$ & C15:0 & $0.69 \pm 0.02$ \\
Oxalic acid & $537 \pm 5$ & C16:0 & $16.75 \pm 0.07$ \\
Quinic acid & $744 \pm 42$ & C16:1 & $1.044 \pm 0.003$ \\
Malic acid & $355 \pm 5$ & C17:0 & $0.41 \pm 0.01$ \\
Shikimic acid & $5.78 \pm 0.03$ & C18:0 & $4.167 \pm 0.001$ \\
Citric acid & $276 \pm 4$ & C18:1n9 & $5.20 \pm 0.02$ \\
Fumaric acid & $2.7 \pm 0.1$ & C18:2n6 & $6.61 \pm 0.01$ \\
Ascorbic acid & $2.3 \pm 0.1$ & C18:3n3 & $53.79 \pm 0.04$ \\
Total & $1923 \pm 28$ & C20:0 & $3.436 \pm 0.005$ \\
Tocopherols $(\mathbf{m g}$ per $\mathbf{1 0 0} \mathbf{g} \mathbf{f w})$ & C20:2 & $0.189 \pm 0.002$ \\
$\alpha$-Tocopherol & $4.1 \pm 0.1$ & C20:3n3 & $0.295 \pm 0.004$ \\
$\beta$-Tocopherol & $0.38 \pm 0.02$ & C21:0 & $0.402 \pm 0.005$ \\
$\gamma$-Tocopherol & $34.6 \pm 0.7$ & C22:0 & $1.22 \pm 0.02$ \\
$\delta$-Tocopherol & $0.26 \pm 0.03$ & C23:0 & $0.26 \pm 0.01$ \\
Total & $39.3 \pm 0.8$ & C24:0 & $0.44 \pm 0.02$ \\
& & SFA & $\mathbf{3 2 . 8 8} \pm \mathbf{0 . 0 8}$ \\
& & MUFA & $\mathbf{6 . 2 4} \pm \mathbf{0 . 0 3}$ \\
& & PUFA & $\mathbf{6 0 . 8 8} \pm \mathbf{0 . 0 5}$
\end{tabular}

Caproic acid (C6:0); capric acid (C10:0); lauric acid (C12:0); tridecylic acid (C13:0); myristic acid (C14:0); pentadecanoic acid (C15:0); palmitic acid (C16:0); palmitoleic acid (C16:1); heptadecanoic acid (C17:0); stearic acid (C18:0); oleic acid (C18:1n9); linoleic acid (C18:2n6); $\alpha$-linolenic acid (C18:3n3); arachidic acid (C20:0); eicosadienoic acid (C20:2); eicosatrienoic acid (C20:3n3); heneicosylic acid (C21:0); behenic acid (C22:0); tricosanoic acid (C23:0); and lignoceric acid (C24:0). SFA - saturated fatty acids; MUFA monounsaturated fatty acids; and PUFA - polyunsaturated fatty acids.

were found in the same amounts $(23 \pm 1$ and $20 \pm 1 \mathrm{mg}$ per $100 \mathrm{~g} \mathrm{fw}$, respectively) and total sugars showed, in general, a low amount (102 $\pm 1 \mathrm{mg}$ per $100 \mathrm{~g} \mathrm{fw})$. No previous studies on the sugar composition of this variety are found in the literature. Nevertheless, Pereira et al. ${ }^{25}$ studied the chemical composition of green $O$. basilicum and the results showed the presence of the same sugars: fructose, glucose, sucrose and trehalose. In contrast to the present study, sucrose was the compound found in the highest concentration $(1.02 \pm 0.07 \mathrm{~g}$ per $100 \mathrm{~g} \mathrm{dw})$, followed by trehalose $(0.85 \pm 0.05 \mathrm{~g}$ per $100 \mathrm{~g} \mathrm{dw})$, fructose $(0.52 \pm 0.01 \mathrm{~g}$ per $100 \mathrm{~g} \mathrm{dw})$ and glucose $(0.40 \pm 0.01 \mathrm{~g}$ per $100 \mathrm{~g} \mathrm{dw}$ ). On the other hand, a study performed by Carocho et al., ${ }^{7}$ which investigated basil leaves as a functional and preserving ingredient for "Serra da Estrela" cheese, described that the most abundant sugar in green $O$. basilicum decoctions was fructose $\left(12 \pm 1 \mathrm{mg} \mathrm{g}^{-1}\right.$ of lyophilized decoction), followed by sucrose and glucose $(11.7 \pm 0.4$ and $5.8 \pm$ $0.6 \mathrm{mg} \mathrm{\textrm {g } ^ { - 1 }}$ of lyophilized decoction, respectively). Although these results refer to the same species, the observed differences could be explained by the studied varieties, as also the used extraction methods.

Organic acids were also evaluated and the results revealed the presence of oxalic, quinic, malic, shikimic, citric, fumaric, and ascorbic acids (Table 2). Quinic acid was the most abun- dant compound (744 $\pm 42 \mathrm{mg}$ per $100 \mathrm{~g}$ fw), followed by oxalic $(537 \pm 5 \mathrm{mg}$ per $100 \mathrm{~g} \mathrm{fw})$, malic $(355 \pm 5 \mathrm{mg}$ per $100 \mathrm{~g} \mathrm{fw})$, and citric (276 $\pm 4 \mathrm{mg}$ per $100 \mathrm{~g} \mathrm{fw}$ ) acids. Otherwise, shikimic, fumaric and ascorbic acids revealed the lowest concentrations, and the total concentration in organic acids was $1923 \pm 28 \mathrm{mg}$ per $100 \mathrm{~g}$ fw.

The most abundant organic acids have been reported to have numerous bioactive functions. Quinic acid has demonstrated to have therapeutic properties, which include radio-protective activity, and anti-diabetic, anti-neuroinflammatory, and antioxidant effects, ${ }^{26}$ while oxalic acid is one of the strongest and most abundant organic acids in nature, being studied among different research areas. This organic acid has demonstrated antioxidant properties and also the capacity of slowing down the aging of many fruits and vegetables. ${ }^{27}$ Malic acid has been widely used in different industries, such as food, chemical, pharmaceutical industries, and also in agriculture. Moreover, studies also report its application in metal cleaning, textile finishing, water treatment and the synthesis of poly $\beta$-Lmalic acid (applied as biodegradable plastic). ${ }^{28}$ Regarding citric acid, several studies report its strong antimicrobial potential, as well as its use in the treatment of burn infections. $^{29}$

The organic acid profile of a green $O$. basilicum decoction has been previously evaluated, ${ }^{7}$ revealing the presence of oxalic, quinic, malic, shikimic and citric acids. Also in this study, the main organic acid was quinic acid $\left(180 \pm 5 \mathrm{mg} \mathrm{g}^{-1}\right.$ of lyophilized decoction), followed by oxalic, malic, citric and shikimic acids $\left(98 \pm 4,54 \pm 3,38 \pm 1\right.$ and $2.92 \pm 0.03 \mathrm{mg} \mathrm{g}^{-1}$ of lyophilized decoction, respectively), which is the order of abundancy of the compounds in accordance with that herein reported. Moreover, to the authors' best knowledge there are no previous reports regarding the organic acid composition in the red rubin basil variety, conferring novelty to the present study.

The tocopherol isoforms $\alpha$-, $\beta$-, $\gamma$ - and $\delta$-tocopherols were all detected in this $O$. basilicum variety (Table 2), but with $\gamma$-tocopherol as the most abundant molecule $(34.6 \pm 0.7 \mathrm{mg}$ per $100 \mathrm{~g} \mathrm{fw})$, followed by $\alpha$-tocopherol, $\beta$-tocopherol and $\delta$-tocopherol, presenting a total concentration of $39.3 \pm 0.8 \mathrm{mg}$ per $100 \mathrm{~g}$ fw.

All isoforms of tocopherols ( $\alpha-, \beta-, \gamma-$, and $\delta$-) are synthesized and stored in plant leaves and seeds, exercising antioxidant function. ${ }^{30}$ These molecules are receiving growing attention in different industrial sectors, namely, the food, cosmetic and pharmaceutical industries. In the food industry, this vitamin is used to increase the shelf life and stability of foods, and therapeutically it exhibits photoprotection and antioxidant properties, and hypolipidemic, antiatherogenic, antihypertensive, allergic dermatitis suppressive, neuroprotective, and anti-inflammatory activities. ${ }^{31}$ In particular, $\gamma$-tocopherol is a strong antioxidant and shows anti-inflammatory, anti-proliferative, and pro-apoptotic effects. ${ }^{32}$

Gómez-Coronado et al. ${ }^{33}$ studied the contents of tocopherols in edible products of plant origin, and these authors described the presence of $\alpha$-tocopherol (4.05 mg per $100 \mathrm{~g}$ 
fresh leaves) and $\gamma$-tocopherol (0.69 $\mathrm{mg}$ per $100 \mathrm{~g}$ fresh leaves) in the green $O$. basilicum species. These values demonstrated that the basil variety studied herein has a higher content of tocopherols (in $\alpha$ - and $\gamma$ - isoforms). The study of the tocopherol profile in O. basilicum var. purpurascens leaves also confers novelty to this manuscript, since no studies were found in the literature that describe the composition of this vitamin in this variety.

The fatty acid characterization was also performed and the results are presented in Table 2 . Twenty fatty acids were identified in the studied sample, with $\alpha$-linolenic acid (C18:3n3) exhibiting the highest percentage (53.79 $\pm 0.04 \%)$. Other molecules were also detected in a significant percentage, such as palmitic acid (C16:0, $16.75 \pm$ 0.07\%), linoleic acid (C18:2n6, $6.61 \pm 0.01 \%)$, and oleic acid (C18:1n9, $5.20 \pm 0.02 \%)$. The remaining fatty acids identified showed concentrations below $5 \%$.

According to some authors, $\alpha$-linolenic acid can be acquired through regular intake of some foods, such as seed oils, beans, walnuts, and leafy vegetables, and has been described to have properties beneficial to health, demonstrating therapeutic properties, such as cardiovascular-protective, anticancer, neuro-protective, anti-osteoporotic, anti-inflammatory, and hypocholesterolemic effects, hypolipidemic activity, antiarrhythmic and serum cholesterol-lowering effects, antioxidant activity, and decreasing the risk of mild dementia. ${ }^{34}$

Polyunsaturated fatty acids (PUFA, $60.88 \pm 0.05 \%$ ) were also the main group of fatty acids present in the sample, followed by saturated fatty acids (SFA, $32.88 \pm 0.08 \%$ ), and monounsaturated fatty acids (MUFA, $6.24 \pm 0.03 \%$ ).

These results are in agreement with those reported by Kadan et al. ${ }^{35}$ which evaluated the chemical composition of the methanolic extract of the $O$. basilicum green variety and $\alpha$-linolenic, palmitic and linoleic acids were also identified as the main compounds, with concentrations of 4.39, 4.26 and $1.38 \%$, respectively. Pereira et al. ${ }^{25}$ studied a green $O$. basilicum variety and in the fatty acid evaluation PUFA were also the major group, followed by SFA and finally MUFA, revealing $\alpha$-linolenic acid (55.89 $\pm 0.26 \%)$, linoleic acid $(9.84 \pm 0.03 \%)$ and palmitic acid $(17.79 \pm 0.31 \%)$ at the highest concentrations.

Polyunsaturated fatty acids are essential molecules for human health, being important for neurogenesis, memory, emotions, and for the development and maintenance of the brain structure during embryonic and adult stages. ${ }^{36}$ Also, they play a significant role in the regulation of the endocannabinoid system, which is a major regulator of mood and emotions. ${ }^{36}$ Studies have reported that insufficient consumption of PUFA increases the probability of age-related diseases, such as cardiovascular, cancer, brain, and inflammatory diseases, deficiency symptoms, and cognitive, psychiatric, antisocial, and other disorders. ${ }^{37}$ To the authors' best knowledge there are no previous reports regarding the fatty acid composition in the red rubin basil variety.

\subsection{Phenolic compound composition of the leaf extract}

The phenolic compound profile of red rubin basil is shown in Table 3. A total of twenty-six compounds were identified
(Fig. 1), and divided into thirteen non-anthocyanin phenolic compounds and thirteen anthocyanins. Among the non-anthocyanin compounds, three phenolic acids, nine flavanone derivatives (eriodictyol and naringenin derivatives), and one flavanonol were identified. Concerning the anthocyanin compounds, twelve cyanidin glycoside derivatives were identified, which were the main compounds; nevertheless, one pelargonidin derivative was also identified.

Regarding flavonoid derivatives, compounds 2, 4, 6 ([M $\mathrm{H}]^{-}$at $\left.m / z 449\right), 5\left([\mathrm{M}-\mathrm{H}]^{-}\right.$at $\left.m / z 463\right), 9$ and $12\left([\mathrm{M}-\mathrm{H}]^{-}\right.$at $\mathrm{m} / z$ 535) were identified as eriodictyol glycosides based on their UV spectra ( $\lambda_{\max }$ around $285 \mathrm{~nm}$ with a shoulder at $330 \mathrm{~nm}$ ) and the production of an $\mathrm{MS}^{2}$ fragment ion at $\mathrm{m} / \mathrm{z}$ 287. Peaks 2, 4 and 6 were identified as eriodictyol-O-hexoside isomers, in which the $\mathrm{MS}^{2}$ fragment revealed the loss of a hexosyl $(\mathrm{m} / \mathrm{z}$ at $287 ;-162 \mathrm{u})$ residue. The position and nature of the hexosyl moiety could not be identified, because the retention time of these compounds did not correspond to any of the standards available. Similarly, peak 5 presented an $\mathrm{MS}^{2}$ fragment at $m / z 287$ with the loss of a glucuronyl residue $(-176 \mathrm{u})$, which is tentatively identified as eriodictyol-O-glucuronide. Compounds 9 and 12 presented a pseudomolecular ion $86 \mathrm{u}$ (malonyl moiety) higher than compounds 2, 4 and 6, both peaks being tentatively identified as eriodictyol- $O$-malonylhexoside. Similarly, peaks 7,8 and 13 were identified as naringenin ( $\lambda_{\max }$ around $353 \mathrm{~nm}, \mathrm{MS}^{2}$ fragment at $\mathrm{m} / z$ 271) glycosides, and peak 1 as a taxifolin $\left(\lambda_{\max }\right.$ around $350 \mathrm{~nm}, \mathrm{MS}^{2}$ fragment at $m / z$ 303) glycoside. Whereas peaks $1\left([\mathrm{M}-\mathrm{H}]^{-}\right.$at $m / z 465)$ and $7\left([\mathrm{M}-\mathrm{H}]^{-}\right.$at $\left.m / z 433\right)$ were tentatively identified as taxifolin- $O$-hexoside and naringenin- $O$-hexoside, respectively, compound $13\left([\mathrm{M}-\mathrm{H}]^{-}\right.$at $\mathrm{m} / \mathrm{z}$ 519) was tentatively identified as naringenin- $O$-malonylhexoside. Compound 8 $\left([\mathrm{M}-\mathrm{H}]^{-}\right.$at $\left.m / z 565\right)$ presented the following fragmentation ions: 445 ([M $\left.-\mathrm{H}-120]^{-}\right), 313\left([\mathrm{M}-\mathrm{H}-120-132]^{-}\right)$, and 271 $\left([\mathrm{M}-\mathrm{H}-294]^{-}\right)$, which could be identified as naringenin$\mathrm{C}$-hexosyl-O-acetyl-pentoside; thus no compound with such characteristics has been described in the literature; therefore, this compound was simply identified as a naringenin glycoside derivative.

To the author's best knowledge there are no previous reports mentioning the identified flavonoid compounds in O. basilicum var. purpurascens leaves.

Concerning the phenolic acids, compound 10 was positively identified as rosmarinic acid considering the comparison of its retention time, UV-Vis spectrum, and MS fragmentation pattern with the commercial standard. Compound 11 revealed similar characteristics and has been tentatively identified as a rosmarinic acid isomer. Compound $3\left([\mathrm{M}-\mathrm{H}]^{-}\right.$at $\left.\mathrm{m} / \mathrm{z} 473\right)$ presented a fragmentation pattern that allowed assigning this compound as chicoric acid (dicaffeoyltartaric acid). Compounds 3 (chicoric acid) and 10 (rosmarinic acid) have been widely identified in basil samples, with rosmarinic acid being one of the main non-anthocyanin phenolic compounds present in red rubin basil. ${ }^{8,12,13,38}$

The identified anthocyanin compounds represent $19 \%$ of the identified phenolic compounds. Compounds 16-23 and 
Table 3 Retention time $\left(R_{\mathrm{t}}\right)$, wavelengths of maximum absorption in the UV-Vis region $\left(\lambda_{\max }\right)$, tentative identification and quantification of phenolic compounds in the $O$. basilicum var. purpurascens hydroethanolic extract (mean \pm SD)

\begin{tabular}{|c|c|c|c|c|c|c|}
\hline Peak & $R_{\mathrm{t}}(\min )$ & $\lambda_{\max }(\mathrm{nm})$ & {$[\mathrm{M}-\mathrm{H}]^{-}$} & $\begin{array}{l}\text { Main fragment ESI- MSn } \\
\text { [intensity }(\%)]\end{array}$ & Tentative identification & $\begin{array}{l}\text { Quantification } \\
\left(\mathrm{mg} \mathrm{g}^{-1}\right)\end{array}$ \\
\hline 1 & 6.7 & $287, \operatorname{sh} 320$ & 465 & 303(100) & Taxifolin-O-hexoside $^{a}$ & $1.52 \pm 0.02$ \\
\hline 2 & 10.9 & $285, \operatorname{sh} 330$ & 449 & $287(100)$ & Eriodictyol-O-hexoside isomer $1^{b}$ & $1.6 \pm 0.1$ \\
\hline 4 & 14.1 & 325 & 473 & $311(98), 293(100)$ & Chicoric acid ${ }^{c}$ & $3.3 \pm 0.1$ \\
\hline 5 & 15.2 & $285, \operatorname{sh} 325$ & 463 & $287(100)$ & Eriodictyol- $O$-glucuronide $^{b}$ & $1.48 \pm 0.02$ \\
\hline 6 & 16.0 & $285, \operatorname{sh} 330$ & 449 & $287(100)$ & Eriodictyol-O-hexoside isomer $3^{b}$ & $12.7 \pm 0.4$ \\
\hline 9 & 20.6 & $285, \operatorname{sh} 335$ & 535 & $491(100), 287(10)$ & Eriodictyol-O-malonylhexoside isomer $1^{b}$ & $20.4 \pm 0.4$ \\
\hline 10 & 21.9 & 327 & 359 & $197(28), 179(42), 161(100), 133(5)$, & Rosmarinic acid $^{d}$ & $95 \pm 1$ \\
\hline 11 & 23.0 & 323 & 359 & $197(26), 179(35), 161(100), 133(6)$ & Rosmarinic acid isomer ${ }^{d}$ & $9.6 \pm 0.4$ \\
\hline 12 & 24.5 & $290, \operatorname{sh} 330$ & 535 & $491(60), 287(100)$ & Eriodictyol- $O$-malonylhexoside isomer $2^{b}$ & $2.67 \pm 0.03$ \\
\hline \multirow[t]{2}{*}{13} & 25.8 & $284, \operatorname{sh} 330$ & 519 & 475(100), 271(12) & Naringenin-O-malonylhexoside ${ }^{b}$ & $14.69 \pm 0.01$ \\
\hline & & & & & TPA & $108 \pm 2$ \\
\hline
\end{tabular}

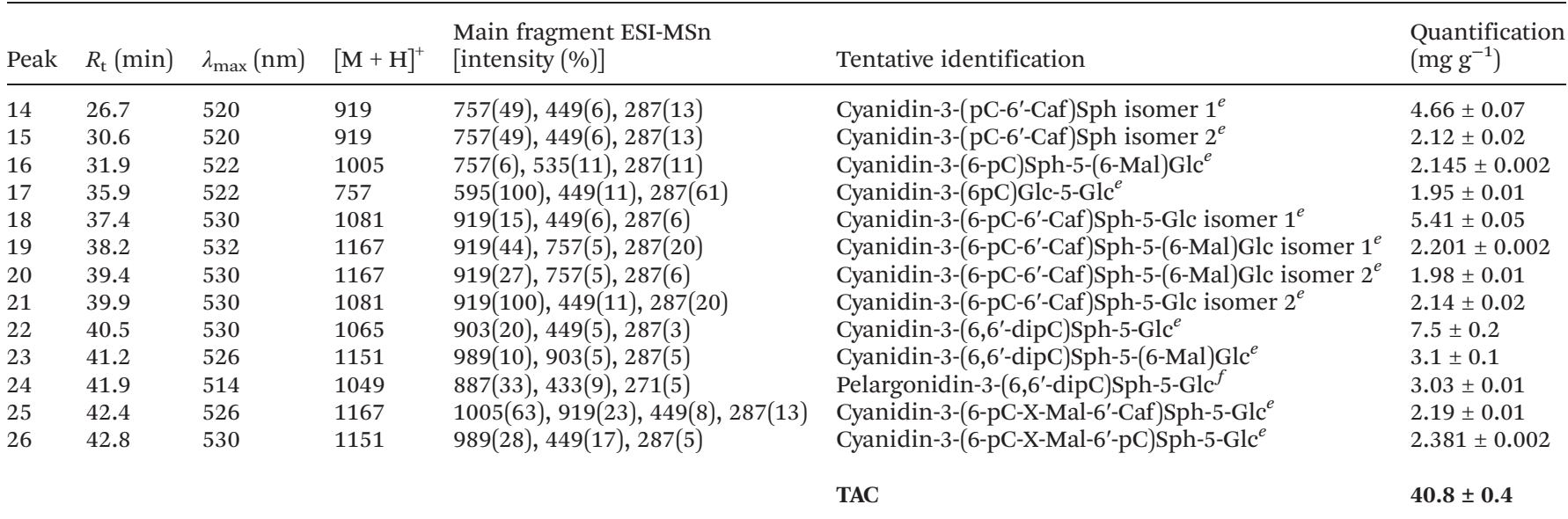

$R_{\mathrm{t}}$ - retention time; TPA - total phenolic acids; TFNA - total flavonoids non-anthocyanins; TPCNA - total phenolic compounds non-anthocyanins; TAC - total anthocyanin compounds. pC - p-coumaroyl; Sph - sophoroside; Caf - caffeoyl; Mal - malonyl; Glc - glucoside. Calibration curves used: ${ }^{a}$ Taxifolin $\left(y=203766 x-208383 ; R^{2}=1\right) .{ }^{b}$ Naringenin $\left(y=18433 x+78903 ; R^{2}=0.9998\right) .{ }^{c}$ Caffeic acid $\left(y=388345 x+406369 ; R^{2}=0.994\right)$. ${ }^{d}$ Rosmarinic acid $\left(y=191291 x-652903 ; R^{2}=0.999\right) .{ }^{e}$ Cyanidin-3-O-glucoside $\left(y=97787 x-743469 ; R^{2}=0.999\right) .{ }^{f}$ Pelargonidin-3-O-glucoside $\left(y=43781 x-275315 ; R^{2}=0.999\right)$.

25-26 were identified considering previous findings described in the literature by Luna et al. ${ }^{38}$ and Phippen and Simon. ${ }^{14}$ Compounds 14 and $15\left([\mathrm{M}-\mathrm{H}]^{-}\right.$at $m / z$ 919) presented both a pseudomolecular ion with less -162 u (hexosyl moiety) in comparison with peaks 18 and $21\left([\mathrm{M}-\mathrm{H}]^{-}\right.$at $\left.\mathrm{m} / \mathrm{z} 1081\right)$ being tentatively identified as cyanidin-3-(pC-6'-Caf)Sph isomers 1 and 2. Peak $24\left([\mathrm{M}-\mathrm{H}]^{-}\right.$at $m / z$ 1049) presented a similar fragmentation pattern to peak 22; thus it presented a different aglycone (pelargonidin derivative), being tentatively identified as pelargonidin-3-(6,6'-dipC)Sph-5-Glc.

Among the thirteen identified anthocyanins, cyanidin-3(6,6'-dipC)Sph-5-Glc was the main anthocyanin compound, followed by cyanidin-3-(6-pC-6'-Caf)Sph-5-Glc isomer 1 .

Phippen and Simon ${ }^{14}$ quantified fourteen anthocyanins in purple basil varieties, including red rubin basil, with the total content of anthocyanins being $17.44 \pm 0.80 \mathrm{mg}$ per $100 \mathrm{~g}$ fresh tissue. Nevertheless, these values are not comparable to those herein reported, because the results are differently expressed. This is the first report quantifying the anthocyanin content in O. basilicum var. purpurascens leaves.

\subsection{Antimicrobial and hepatotoxic activities of leaf extracts}

The results obtained for the antimicrobial activity of the hydroethanolic extracts of $O$. basilicum var. purpurascens leaves are presented in Table 4 . The red rubin basil extract was tested against a panel of pathogenic bacteria (Gram-positive and Gram-negative bacteria) and fungi. The results showed antibacterial capacity for all the studied bacterial strains, highlighting Bacillus cereus with the lowest MIC $\left(0.10 \mathrm{mg} \mathrm{mL}^{-1}\right)$ and MBC $\left(0.15 \mathrm{mg} \mathrm{mL}^{-1}\right)$ values, thus with higher bacteriostatic and bactericidal effects. Moreover, the extracts also revealed high activity against Staphylococcus aureus, Listeria monocytogenes, Escherichia coli, and Enterobacter cloacae (MIC and MBC values of 0.15 and $0.30 \mathrm{mg} \mathrm{mL}^{-1}$, respectively). 

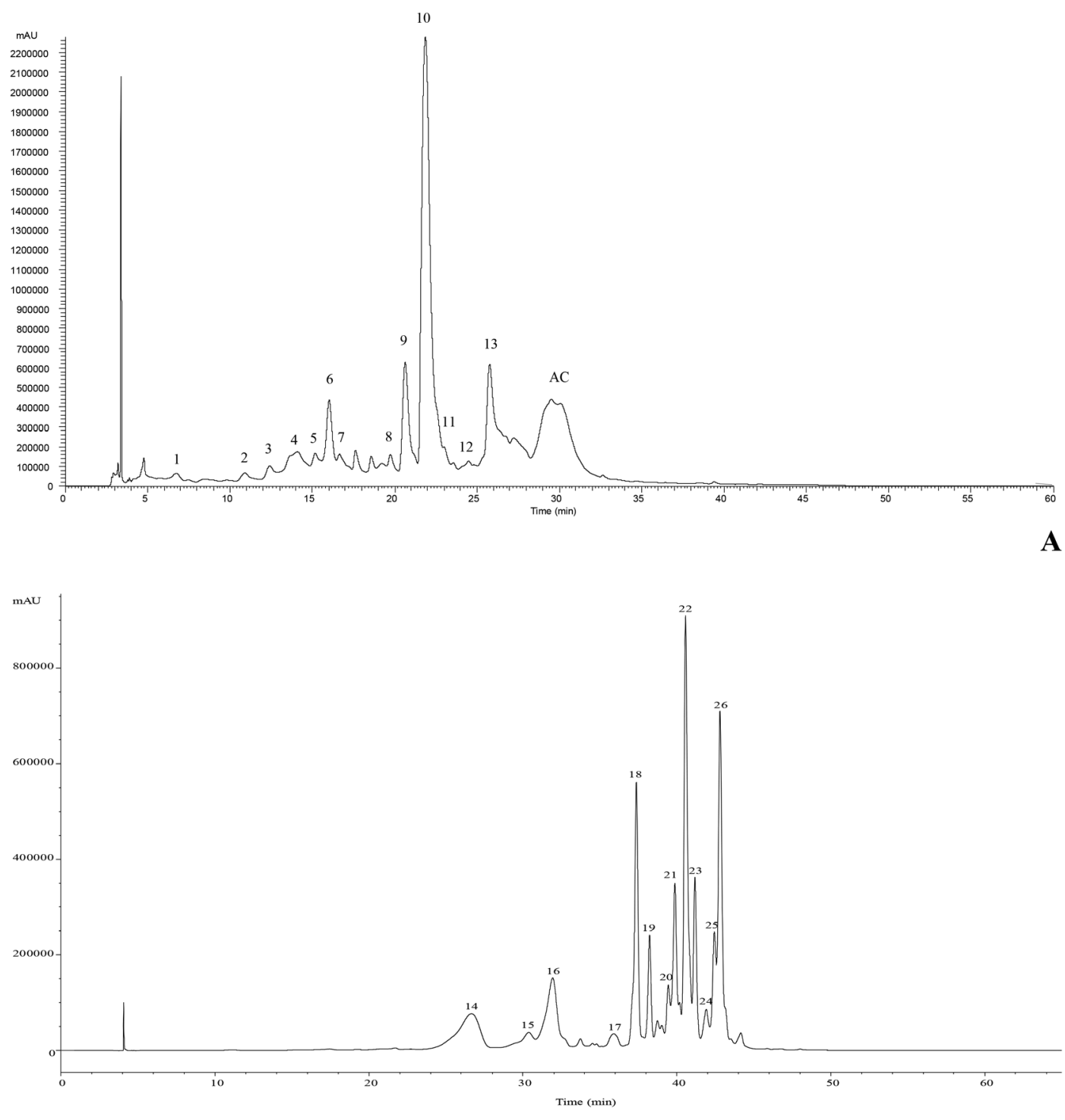

B

Fig. 1 Phenolic compound profile of $O$. basilicum var. purpurascens hydroethanolic extracts recorded at $280 \mathrm{~nm}$ (A) and $520 \mathrm{~nm}$ (B). The compounds names, corresponding to each peak represented in this figure, are present in Table 3 (AC - anthocyanin compounds - not quantified using this methodology).

The antifungal evaluation of the hydroethanolic extract also showed high potential against all the tested yeast samples, with fungicidal effects in all cases. Aspergillus ochraceus was the most susceptible strain with MIC and MFC values of $0.037 \mathrm{mg} \mathrm{mL}^{-1}$ and $0.075 \mathrm{mg} \mathrm{mL}^{-1}$, respectively. The same fungicidal effect was obtained for Aspergillus fumigatus (MFC = $0.075 \mathrm{mg} \mathrm{mL}^{-1}$ ).

Comparing the extract results with those of the positive controls, in the majority of the tested bacterial and yeast strains, MIC and MBC/MFC values were much lower, representing a higher antimicrobial activity of the extract in comparison with the controls.

Moreover, Carocho et al. ${ }^{7}$ studied the antimicrobial activity of green basil decoctions, showing positive results regarding antibacterial and antifungal activities. In this study, Listeria monocytogenes was the most sensitive bacteria, revealing MIC values of $0.125 \mathrm{mg} \mathrm{mL}{ }^{-1}$, while Penicillium ochlochloron was the most sensitive yeast (MIC value of $0.062 \mathrm{mg} \mathrm{mL}^{-1}$ for the aqueous extract of basil).

The hydroalcoholic extracts have a rich content of phenolic compounds, which have been described to show high antimicrobial activity. ${ }^{39}$ The presence of rosmarinic acid as the major phenolic compound can probably explain the antimicrobial activity of red rubin basil. Previous studies have reported several biological properties of this phenolic acid, namely antibacterial activity. ${ }^{40}$ These properties arouse interest in this molecule, as well as in red rubin basil, which may be a natural source of this phenolic compound. 
Table 4 Antibacterial (MIC and MBC, $\mathrm{mg} \mathrm{mL}^{-1}$ ) and antifungal (MIC and MFC, $\mathrm{mg} \mathrm{mL}^{-1}$ ) activities of the O. basilicum var. purpurascens hydroethanolic extract

Antibacterial activity

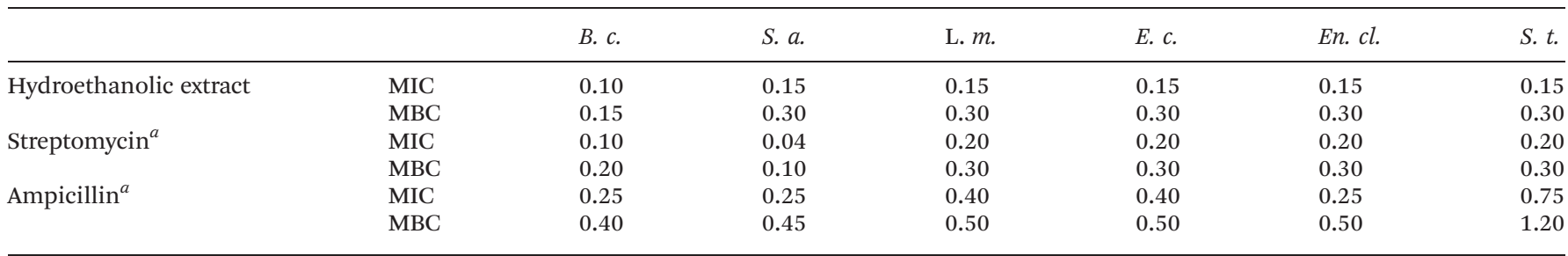

Antifungal activity

\begin{tabular}{|c|c|c|c|c|c|c|c|}
\hline & & A. fun. & A. $o$. & A. $n$. & P. $f$. & P. $o$ & P. v. $c$ \\
\hline & MFC & 0.075 & 0.075 & 0.15 & 0.15 & 0.15 & 0.15 \\
\hline \multirow[t]{2}{*}{ Bifonazole $^{a}$} & MIC & 0.15 & 0.10 & 0.15 & 0.20 & 0.20 & 0.10 \\
\hline & MFC & 0.20 & 0.20 & 0.20 & 0.25 & 0.25 & 0.20 \\
\hline
\end{tabular}

${ }^{a}$ Positive controls; B. c.: Bacillus cereus; S. a.: Staphylococcus aureus; L. m.: Listeria monocytogenes; E. c.: Escherichia coli; En. cl.: Enterobacter cloacae; S. t.: Salmonella typhimurium; A. fum.: Aspergillus fumigatus; A. o.: Aspergillus ochraceus; A. n.: Aspergillus niger; P. f.: Penicillium funiculosum; P. o.: Penicillium ochrochloron; P. v. c.: Penicillium verrucosum var. cyclopium; MIC - minimum inhibitory concentration; MBC - minimum bactericidal concentration; MFC - minimum fungicidal concentration.

For the hepatotoxicity assay, no toxicity was detected using the PLP2 cell line (porcine liver primary cells), up to the maximal tested concentration $\left(\mathrm{GI}_{50}\right.$ values of $\left.>400 \mu \mathrm{g} \mathrm{mL} \mathrm{g}^{-1}\right)$.

To the best of the authors' knowledge no other studies have been performed regarding the antimicrobial activity and hepatoxicity of the hydroethanolic extract of $O$. basilicum var. purpurascens leaves.

\section{Conclusions}

Ocimum basilicum var. purpurascens (red rubin basil) is a variety of great interest, for not only its aromatic and medicinal characteristics, but also its natural pigments. Several studies were found in the literature regarding the $O$. basilicum species; however, few studies have been described regarding the red rubin basil variety. Lyophilisation proved to be a good drying process, because it causes less colour loss. Concerning the nutritional value, it was verified that it has a higher concentration of carbohydrates and a lower fat content. In the chemical composition, several molecules of interest were identified, highlighting glucose and quinic acid as the main free sugars and organic acids, respectively. Concerning tocopherols, four isoforms were found in red rubin basil, with $\gamma$-tocopherol as the main one, which has been described as a strong antioxidant, with health benefits. $\alpha$-Linolenic acid was the prevalent fatty acid, which leads to higher PUFA amounts, being described as health-promoting compounds due to their bioactive potential, such as anti-inflammatory, antioxidant, and cytotoxic properties.

The hydroethanolic extract of red rubin basil presented twenty-six phenolic compounds, thirteen non-anthocyanin molecules, with rosmarinic acid as the major compound, and thirteen anthocyanins, with cyanidin-3-(6,6'-di-p-coumaroyl)sophoroside-5-glucoside being the main compound. The richness in these compounds could be related to its high antimicrobial activity, which revealed positive results, that is, bacteriostatic/fungistatic and bactericidal/fungicidal effects. Moreover, up to the maximal tested concentration, red rubin basil did not show toxicity for porcine liver primary cells.

These results promote the interest in the accomplishment of more studies regarding $O$. basilicum varieties, highlighting the potential of red rubin basil as a source of natural and bioactive ingredients for several industrial sectors.

\section{Conflicts of interest}

The authors declare that they have no conflict of interest.

\section{Acknowledgements}

The authors are grateful to the Foundation for Science and Technology (FCT, Portugal) and FEDER under Program PT2020 for financial support to CIMO (UID/AGR/00690/ 2019). L. Barros and C. Calhelha also thank the National funding by FCT, P. I., through the institutional scientific employment program-contract for their contracts. The authors are also grateful to the Interreg España-Portugal for financial support through the project 0377_Iberphenol_6_E; to the European Regional Development Fund (ERDF) through the Regional Operational Program North 2020, within the scope of Project NORTE-01-0145-FEDER-023289: DeCodE and project 
Mobilizador Norte-01-0247-FEDER-024479: ValorNatural®; and to the Serbian Ministry of Education, Science and Technological development for grant No. 173032.

\section{References}

1 J. H. Yopp, H. Lambers, R. Schmid, G. M. Woodwell, G. W. Rothwell and W. C. Dickison, Plant - Biology, Encyclopedia Britannica, 2018.

2 K. R. McCance, P. M. Flanigan, M. M. Quick and E. D. Niemeyer, Influence of plant maturity on anthocyanin concentrations, phenolic composition, and antioxidant properties of 3 purple basil (Ocimum basilicum L.) cultivars, J. Food Compos. Anal., 2016, 53, 30-39.

3 D. B. Rodriguez-Amaya, Natural food pigments and colorants, Curr. Opin. Food Sci., 2016, 7, 20-26.

4 N. Martins, C. L. Roriz, P. Morales, L. Barros and I. C. F. R. Ferreira, Food colorants: Challenges, opportunities and current desires of agro-industries to ensure consumer expectations and regulatory practices, Trends Food Sci. Technol., 2016, 52, 1-15.

5 P. Ongkowijoyo, D. A. Luna-Vital and E. Gonzalez de Mejia, Extraction techniques and analysis of anthocyanins from food sources by mass spectrometry: An update, Food Chem., 2018, 250, 113-126.

6 C. Gerardi, N. Tommasi, C. Albano, F. Blando, L. Rescio, E. Pinthus and G. Mita, Prunus mahaleb L. fruit extracts: a novel source for natural food pigments, Eur. Food Res. Technol., 2015, 241, 683-695.

7 M. Carocho, L. Barros, J. C. M. Barreira, R. C. Calhelha, M. Soković, V. Fernández-Ruiz, C. Buelga, O. Morales and I. C. F. R. Ferreira, Basil as functional and preserving ingredient in "serra da Estrela" cheese, Food Chem., 2016, 207, 51-59.

8 P. M. Flanigan and E. D. Niemeyer, Effect of cultivar on phenolic levels, anthocyanin composition, and antioxidant properties in purple basil (Ocimum basilicum L.), Food Chem., 2014, 164, 518-526.

9 H. A. Bhatti, Y. Tehseen, K. Maryam, M. Uroos, B. S. Siddiqui, A. Hameed and J. Iqbal, Identification of new potent inhibitor of aldose reductase from Ocimum basilicum, Bioorg. Chem., 2017, 75, 62-70.

10 E. M. G. El-Hadidy and O. F. A. Mostafa, Phytochemical Evaluation of Two Cultivated Basil (Ocimum basilicum L.) Green and Red rubin leaves, Egypt. J. Agric. Res., 2011, 87, 203-215.

11 B. Murillo-Amador, A. Nieto-Garibay, E. Troyo-Diéguez, A. Flores-Hernández, M. V. Cordoba-Matson and A. Villegas-Espinoza, Proximate analysis among 24 Ocimum cultivars under two cultivation environments: A comparative study, J. Food, Agric. Environ., 2013, 11, 2842-2848.

12 M. Moghaddam and L. Mehdizadeh, Variability of total phenolic, flavonoid and rosmarinic acid content among Iranian basil accessions, LWT-Food Sci. Technol., 2015, 63, 535-540.
13 S. Srivastava, A. Adholeya, X. A. Conlan and D. M. Cahill, Acidic Potassium Permanganate Chemiluminescence for the Determination of Antioxidant Potential in Three Cultivars of Ocimum basilicum, Plant Foods Hum. Nutr., 2016, 71, 72-80.

14 W. B. Phippen and J. E. Simon, Anthocyanins in Basil (Ocimum basilicum L.), J. Agric. Food Chem., 1998, 46, 1734-1738.

15 E. Pereira, A. L. Antonio, J. C. M. Barreira, L. Barros, A. Bento and I. C. F. R. Ferreira, Gamma irradiation as a practical alternative to preserve the chemical and bioactive wholesomeness of widely used aromatic plants, Food Res. Int., 2015, 67, 338-348.

16 AOAC, AOAC Official Methods of Analysis, AOAC INTERNATIONAL, 20th edn, 2016.

17 L. Barros, E. Pereira, R. C. Calhelha, M. Dueñas, A. M. Carvalho, C. Santos-Buelga and I. C. F. R. Ferreira, Bioactivity and chemical characterization in hydrophilic and lipophilic compounds of Chenopodium ambrosioides L, J. Funct. Foods, 2013, 5, 1732-1740.

18 I. Jabeur, E. Pereira, L. Barros, R. C. Calhelha, M. Soković, M. B. P. P. Oliveira and I. C. F. R. Ferreira, Hibiscus sabdariffa L. as a source of nutrients, bioactive compounds and colouring agents, Food Res. Int., 2017, 100, 717-723.

19 G. A. Gonçalves, A. A. Soares, R. C. G. Correa, L. Barros, C. W. I. Haminiuk, R. M. Peralta, I. C. F. R. Fereira and A. Bracht, Merlot grape pomace hydroalcoholic extract improves the oxidative and inflammatory states of rats with adjuvant-induced arthritis, J. Funct. Foods, 2017, 33, 408-418.

20 M. Carocho, L. Barros, R. C. Calhelha, A. Ćirić, M. Soković, C. Santos-Buelga, P. Morales and I. C. F. R. Ferreira, Melissa officinalis, L. decoctions as functional beverages: a bioactive approach and chemical characterization, Food Funct., 2015, 6, 2240-2248.

21 T. Jiang, Y. Mao, L. Sui, N. Yang, S. Li, Z. Zhu, C. Wang, S. Yin, J. He and Y. He, Degradation of anthocyanins and polymeric color formation during heat treatment of purple sweet potato extract at different pH, Food Chem., 2018, 274, 460-470.

22 M. Xu, C. Du, N. Zhang, X. Shi, Z. Wu and Y. Qiao, Color spaces of safflower (Carthamus tinctorius, L.) for quality assessment, J. Tradit. Chin. Med. Sci., 2016, 3, 168-175.

23 R. de A. B. Lima-Corrêa, M. dos S. Andrade, M. F. das G. F. da Silva, J. T. Freire and M. do C. Ferreira, Thin-layer and vibrofluidized drying of basil leaves (Ocimum basilicum L.): analysis of drying homogeneity and influence of drying conditions on the composition of essential oil and leaf colour, J. Appl. Res. Med. Aromat. Plants, 2017, 7, 54-63.

24 D. Luna-Vital, Q. Li, L. West, M. West and E. Gonzalez de Mejia, Anthocyanin condensed forms do not affect color or chemical stability of purple corn pericarp extracts stored under different pHs, Food Chem., 2017, 232, 639-647.

25 C. Pereira, L. Barros and I. C. F. R. Ferreira, A Comparison of the Nutritional Contribution of Thirty-nine Aromatic Plants used as Condiments and/or Herbal Infusions, Plant Foods Hum. Nutr., 2015, 70, 176-183. 
26 S. A. Jang, D. W. Park, J. E. Kwon, H. S. Song, B. Park, H. Jeon, E. H. Sohn, J. Koo and S. C. Kang, Quinic acid inhibits vascular inflammation in TNF- $\alpha$-stimulated vascular smooth muscle cells, Biomed. Pharmacother., 2017, 96, 563-571.

27 M. Cefola and B. Pace, Application of Oxalic Acid to Preserve the Overall Quality of Rocket and Baby Spinach Leaves during Storage, J. Food Process. Preserv., 2015, 39, 2523-2532.

28 Z. Dai, H. Zhou, S. Zhang, H. Gu, Q. Yang, W. Zhang, W. Dong, J. Ma, Y. Fang, M. Jiang and F. Xin, Current advance in biological production of malic acid using wild type and metabolic engineered strains, Bioresour. Technol., 2018, 258, 345-353.

29 B. Nagoba, M. Davane, R. Gandhi, B. Wadher, N. Suryawanshi and S. Selkar, Treatment of skin and soft tissue infections caused by Pseudomonas aeruginosa-A review of our experiences with citric acid over the past 20 years, Wound Med., 2017, 19, 5-9.

30 A. Azzi, Many tocopherols, one vitamin E, Mol. Aspects Med., 2017, 61, 92-103.

31 R. K. Saini and Y. S. Keum, Tocopherols and tocotrienols in plants and their products: A review on methods of extraction, chromatographic separation, and detection, Food Res. Int., 2016, 82, 59-70.

32 E. Reiter, Q. Jiang and S. Christen, Anti-inflammatory properties of $\alpha$ - and $\gamma$-tocopherol, Mol. Aspects Med., 2007, 28, 668-691.

33 D. J. M. Gómez-Coronado, E. Ibañez, F. J. Rupérez and C. Barbas, Tocopherol measurement in edible products of vegetable origin, J. Chromatogr., A, 2004, 1054, 227-233.
34 K. B. Kim, Y. A. Nam, H. S. Kim, A. W. Hayes and B. M. Lee, $\alpha$-Linolenic acid: Nutraceutical, pharmacological and toxicological evaluation, Food Chem. Toxicol., 2014, 70, 163178.

35 S. Kadan, B. Saad, Y. Sasson and H. Zaid, In vitro evaluation of anti-diabetic activity and cytotoxicity of chemically analysed Ocimum basilicum extracts, Food Chem., 2016, 196, 1066-1074.

36 M. Z. Khan and L. He, The role of polyunsaturated fatty acids and GPR40 receptor in brain, Neuropharmacology, 2017, 113, 639-651.

37 J. Kraic, D. Mihálik, L. Klčová, M. Gubišová, T. Klempová, M. Hudcovicová, K. Ondreičková, M. Mrkvová, M. Havrlentová, J. Gubiš and M. Čertík, Progress in the genetic engineering of cereals to produce essential polyunsaturated fatty acids, J. Biotechnol., 2018, 284, 115122.

38 M. C. Luna, F. Bekhradi, F. Ferreres, M. J. Jordán, M. Delshad and M. I. Gil, Effect of Water Stress and Storage Time on Anthocyanins and Other Phenolics of Different Genotypes of Fresh Sweet Basil, J. Agric. Food Chem., 2015, 63, 9223-9231.

39 A. D. Steiner, A. Vargas, N. Fronza, A. Brandelli and J. H. Z. dos Santos, Antimicrobial activity of some natural extracts encapsulated within silica matrices, Colloids Surf., B, 2017, 160, 177-183.

40 M. Matejczyk, R. Świsłocka, A. Golonko, W. Lewandowski and E. Hawrylik, Cytotoxic, genotoxic and antimicrobial activity of caffeic and rosmarinic acids and their lithium, sodium and potassium salts as potential anticancer compounds, Adv. Med. Sci., 2018, 63, 14-21. 